\title{
Consumer subsequent plan for selection of hospital in the perspective of hospital services and expenditure
}

\author{
Farhana Begum ${ }^{1}$, Shahinul Alam ${ }^{2}$
}

${ }^{1}$ Assistant Professor, Accounting; Assistant Director, Finance and Procurement (Deputation); Directorate of Secondary and Higher Education, Dhaka, Bangladesh. ${ }^{2}$ Associate Professor. Department of Hepatology. Bangabandhu Sheikh Mujib Medical University, Shahbag, Dhaka, Bangladesh.

\section{Abstract}

Further utilization of hospital facility is influenced by the provision of hospital care and cost of services. This study was conducted among patients of public and private hospitals of Dhaka city, Bangladesh to explore the relationship of further utilization of hospital care and cost of services incurred during previous visits. A total 199 patients of 2 private and 2 public hospitals were included. Of them, $100(50.25 \%)$ were from public and $99(49.74 \%)$ from private hospitals. Male: female ratio of the respondents was 111:88. The level of services was scored by patients on a 1-5 Likert scale on the aspects of services of doctors, nurses, other staffs; medicine supply; cleanliness; and investigation facilities. Poor people usually sought the services from public hospitals. About three-quarter of the respondents (76.9 $\%)$ mentioned that they would avail the facility of same hospital for their further ailment. Seventeen patients $(17 \%)$ who were treated in government hospitals will not further utilize the services, and this was significantly higher ( $p$ $0.02)$ in the case of patients from private hospitals $(29.3 \%)$. Regression analysis explored that quality of services $(p=$ $0.000)$ and cost of services $(p=0.001)$ influenced the plan of future consumption of hospital facility and quality of services having stronger influences. This study concludes that further utilization of the hospital facility was strongly influenced by the quality of services and next to that is cost of services. So we recommend for best and successive utilization of hospital services to improve facilities and minimization of cost are the essential needs.

Keywords: Hospital Services, Expenditure, Utilization, Patient satisfaction, Bangladesh.

\section{Introduction}

Rapidly rising cost in health care is an increasing cause of concern across the world. In Bangladesh, healthcare is also experiencing a change, with increasing focus on better quality of medical care services irrespective of cost of it. Improvement of quality health care service inevitably ends with high expenditure. However, when compared with paying power parity and affordability, the cost of medical care is escalating.

In developing countries, governments often subsidize services at public health care facilities and provide them free of charge to users. However, due to lack of governance users still incur large expenditures using the 'free' services. Studies have found that patients incurred substantial out of- pocket expenditures for medicine, food and travel for the use of 'free' public health facilities. ${ }^{1-3}$

Most of the people of Bangladesh are of poor socioeconomic status and they have to avail themselves of the services from public sector. Till now public sector is the only active system at the doorstep level of the poor and middle class people. Most of the people cannot buy the health services of private sector as they are costly. An overwhelming majority of the population in Bangladesh lives below the poverty threshold limiting their access to critical healthcare and other basic needs. ${ }^{4}$

Episodes of illness and ill health may result in substantial medical expenses and trigger impoverishment of households. Cost of healthcare services may deter or delay patients, especially the poor, from seeking appropriate care. Affordability or perceived costs of care are significant factors influencing healthcare behaviors such as choice of the provider and time of care. Difficulty in

\section{Practice Points}

- Further utilization of hospital services could be a measure of service quality provided.

- Consumer of $29.3 \%$ of private hospital and $17 \%$ of public hospital will not return to same hospital in their future ailment.

- Further utilization depends on service provided and cost of services at hospital. Interpersonal variation, treatment outcome and mode of treatment did not influence in decision making of future utilization.

- Service scored by consumer is better in private hospital than that of public hospital in the perspective of nurse service, service of Aya, Ward Boy, cleanliness, laboratory service and supply of medicine. No significant difference in service of doctors.

- Good governance for improving the quality with affordable cost will increase the utilization of health services.

payment of health care expenses can result in the 'distress sale' of property, delay, or abandonment of treatment, and sacrifice expenditures on food and education. ${ }^{3,5}$ Other studies have found that introducing or increasing user fees negatively affects the utilization of public health facilities. ${ }^{6-9}$

Three previous studies have explored issues related to patient expenditures in Bangladesh. ${ }^{3,10,11}$ Nahar et al. ${ }^{3}$ enumerated the patient expenditures and affordability

Correspondence: Dr Shahinul Alam, Associate Professor. Department of Hepatology, Bangabandhu Sheikh Mujib Medical University, Shahbag, Dhaka, Bangladesh. Email: shahinul67@yahoo.com. 
of free maternity services for normal delivery and caesarean section. Killingsworth et al. ${ }^{10}$ explored the linkage between official and unofficial fees in public health facilities, and concluded that these fees had income and equity effects. Stanton \& Clemens ${ }^{10}$ analyzed the user fees in Bangladesh and pointed out the need to further investigate the factors and practices causing patient expenses before institutional implementation of user fees. World Bank and other donors have been advising developing countries to ensure that limited resources not only have an optimal impact on the population's health at affordable cost but also that health services are client-oriented. ${ }^{12-15}$

People usually expect that in case of his/her falling sick they would be taken to a qualified health practitioner or hospital in the quickest possible time, and would receive desired services. Hospital personnel would be courteous and caring, take keen interest in treating patients, create homely and comfortable environment, and order best investigations, and ensure competent care for quickest recovery. Patients expect that they would not have to wait for treatment, which would be free of cost or at an affordable cost, and patients' opinions would be given due importance at every stage of decision-making about care. When these expectations are met, then a sense of satisfaction prevails in the mind and body of the patient. Satisfaction with hospital care is an outcome of hospital experience and is the result of individual evaluation by the patient of the multiple attributes of care in the background of his personal characteristics. ${ }^{16}$

Patient satisfaction is a health care recipient's reaction to salient aspects of the context, process, and result of his service experience. Satisfaction ratings reflect three variables: personal preferences of the patient, patient's expectations, and the realities of care received. ${ }^{17}$ Satisfaction with the realities of care received is affected by many different components of the care: access, cost, competence of care, personal qualities of service providers, participation of patient in decision making about his/her own care, provision of information about the diseases, results of investigations, physical care, catering aspects of hospital care, etc. ${ }^{17}$

Above all, satisfaction and monetary expenditure would influence the subsequent utilization of the health care facility. The aim of the study was to explore the relationship between further utilization of hospital care and cost of services incurred during previous visits among patients of public and private hospitals of Dhaka city, Bangladesh.

\section{Materials and methods}

The study based on both primary and secondary information. Two separate lists of public and private hospitals in Dhaka were obtained. From the first list, Dhaka Medical College and Mitford Hospital were chosen purposively as these two hospitals are reputed to handle patients from all classes and with various health problems. Both the hospitals have the longest experiences of patient management in the capital city. On the other hand, two hospitals were also purposively chosen from the list of private hospitals. These include Ibn Sina Hospital and Central Hospital. Both Ibn Sina and Central Hospital are referral hospitals having sophisticated technology and skilled manpower. These two hospitals are representative of private hospitals of the country, because lower, middle, and rich people can consume the services of these hospitals.

Monthly family income: Total monthly income was calculated by adding income of all the earning members of the family staying together and take food from the same pot. Classification of poor, middle and rich was done as follows:

Poor: Monthly family income of respondent $<$ Tk. 5000.

Middle Class: Monthly family income of respondent from Tk. 5000-20000.

Rich/Solvent: Monthly family income of respondent $>$ Tk.20000.

Primary data was collected from those respondents who had been admitted in hospitals during March to October 2013. The questionnaire was filled in by the respondents if they could understand it and could write themselves. A preliminary questionnaire was first developed in English using Likert scale for scoring quality then translated into Bengali. Service was scored by the consumer as 1 for not at all satisfactory, 2 for somewhat satisfactory, 3 for more or less satisfactory, 4 for appreciable and 5 for excellent. Hospital services were evaluated in the perspective of services doctors, nurses, other staffs, medicine supply, cleanliness and investigation facilities. All the patients were also asked whether he would come back to same hospital to avail the services if he would become ill unluckily. Total 199 patients filled the questionnaire of the study. Out of 199 selected respondents 100 from public and 99 from private hospitals. The total expenditure of treatment was calculated by summating cost of investigation, medicine, transport, baksheesh (tips), surgery, seat rent, service charge and any other cost related to the treatment of the patient.

After the completion of data processing, the data were analyzed using Statistical Package for Social Science version 20 (SPSS Inc. Chicago, IL). In course of descriptive analysis, frequency, mean, standard deviation (SD) and standard error of mean (SEM) were adopted. On the other hand, continuous variables were compared using Independent t-test and categorical data were compared by Chi-square test. Correlation analysis was done for the positive or negative effect of the variables. Factors associated with future return to the same hospital were analyzed by binary logistic regression analysis. One-way ANOVA was done for comparing more than two groups. $p<0.05$ was considered statistically significant.

\section{Results}

\section{Demographic character of the study population}

We have included 50 patients from Dhaka Medical College Hospital, 50 from Mitford Hospital, 50 from Central Hospital and 49 from Ibn Sina Hospital. Out of these 199 respondents; male was 111 and female was 88. Mean age of the respondent was $41.8 \pm 20.1$ years. Poor, middle and rich class was 75 (37.7\%), 107 $(53.8 \%)$ and $17(8.5 \%)$ respectively (Table 1$)$. Most of poor class $(82.7 \%)$ utilized public hospitals, approximately $65 \%$ of middle class visited private 
Begum \& Alam $\boldsymbol{~}$ Consumer satisfaction, hospital care and cost of services

hospitals, and almost all rich class (94.1\%) sought treatment from private hospitals.

Of these respondents, the key occupation was: housewives $(30.7 \%)$, service $(18.6 \%)$, business $(12.6 \%)$, students $(10.6 \%)$, and farmers $(4.5 \%)$. Half of the patients were recruited from medical wards and the other half from surgical wards. During their stay in the hospitals, patients were in floor $(3.5 \%)$, free bed (36.7\%), paying bed (31.7\%), and in cabin $56(28.1 \%)$. Operative treatment was required for $100(50.3 \%)$ patients and others $99(49.7 \%)$ were treated conservatively. At the end of the treatment 39 (19.6\%) were cured, $94(47.2 \%)$ were improved, $35(17.6 \%)$ had no improvement, and $27(13.6 \%)$ rather deteriorated and $4(2 \%)$ died.

\section{Hospital services and cost of services}

Hospital services were scored by the consumer/patients in the aspects of services of doctors, nurses, other staff, cleanliness, investigation facility, and medicine supply were: $3.4 \pm 1.0,3.5 \pm 1.0,3.2 \pm 1.3,3 . \pm 1.0,3.0 \pm 1.2$ and $3.0 \pm 1.2$ respectively. Total score was $19.3 \pm 5.9$ out of 30. Table 2 shows the detail of the scores of service deliveries. Most of the patients considered services

Table 1: Socio-economic Demographic characteristics of the study population

\begin{tabular}{|l|c|}
\hline \multicolumn{1}{|c|}{ Characteristics } & Findings \\
\hline Age (mean \pm SD) in years & $41.8 \pm 20.1$ \\
\hline Sex (Male: Female) & $111: 88$ \\
\hline Socioeconomic condition [n(\%)] & $75(37.7 \%)$ \\
Poor & $107(53.8 \%)$ \\
Middle & $17(8.5 \%)$ \\
Rich & $36(18.1 \%)$ \\
\hline Educational status [n(\%)] & $77(38.7 \%)$ \\
Illiterate & $29(14.6 \%)$ \\
Primary & $31(15.6 \%)$ \\
SSC & $26(13.1 \%)$ \\
HSC & \\
Higher education & $100: 99$ \\
\hline Admitted in hospital & \\
Government: Private &
\end{tabular}

regarding doctors $(41.7 \%)$, nurses $(36.2 \%)$, cleanliness $(42.2 \%)$, investigation facility $(29.1 \%)$, and medicine supply $(26.6 \%)$ as 'more or less satisfactory' and services by other staff (23.6\%) were rated 'appreciable'.

Individual service scored by consumer in Likert scale was significantly higher in private hospitals than that of public hospital (Table 3): Nurse Service (3.8 \pm 1.0 ) and $(3.2 \pm 1.0), t(197)=8.537, p<0.001$, other staff service $(4.0 \pm 1.0)$ and $(1.2 \pm 1.0), \quad t \quad(197)=9.510$, $p<0.001$, cleanliness $(3.7 \pm 1.0)$ and $(3.0 \pm 1.0), t(197)$ $=5.173, p<0.001$, investigation facility $(3.5 \pm 1.0)$ and $(2.5 \pm 1.1), t(197)=6.418, p<0.001$, medicine supply $(3.7 \pm 1.0)$ and $(2.4 \pm 1.1), t \quad(197)=8.107, p<0.001$. Service of doctor was scored higher also in private hospital but that could not reached up to significant level $(p=0.055)$ (Table 3$)$. So total service quality scored by the consumer was significantly $(p<0.0001)$ higher in private hospitals $(22.3 \pm 5.0)$ than that of public hospital (16.9 \pm 5.2$)$.

Cured patients scored the services better than those who were deteriorated or succumbed to death $(p=0.003$ and $p=0.000)$. Poor, middle and rich scored equally to the services. Patients who stayed in paying bed and cabin scored higher than those who stayed in free bed. Surgically treated patients scored the service better than who were treated conservatively.

Costs of services paid by the patients were in the range of 1.25 to 5000 USD with (mean \pm SEM) 485.22 \pm 50.96 USD. Cost was much higher in private hospitals than that of government hospitals. Logically cost of service positively influenced by duration of hospital stay. Cost was higher for surgically treated patients than that of conservatively treated patients. Cost of services was much higher $(p=0.001)$ in cabin $(1027.23 \pm 1060.75)$ USD than in paying bed (487.12 \pm 411.58$)$ USD and free bed (104.31 \pm 153.30$)$ USD.

\section{Subsequent plan of utilization of hospital facility}

We asked every patient at the time of discharge whether he would consume the hospital facility in his further ailment. Approximately $77 \%$ of the patients

Table 2: Service quality scored by respondents

\begin{tabular}{|l|l|l|l|l|l|l|}
\hline \multicolumn{1}{|c|}{ Score of services } & $\begin{array}{c}\text { Doctors } \\
\text { service } \\
\mathbf{n ( \% )}\end{array}$ & $\begin{array}{c}\text { Nurse } \\
\text { service } \\
\mathbf{n}(\%)\end{array}$ & $\begin{array}{c}\text { Other staff } \\
\text { service } \\
\mathbf{n ( \% )}\end{array}$ & $\begin{array}{c}\text { Cleanliness } \\
\mathbf{n}(\%)\end{array}$ & $\begin{array}{c}\text { Investigation } \\
\text { facility } \\
\mathbf{n}(\%)\end{array}$ & $\begin{array}{c}\text { Medicine } \\
\text { supply } \\
\mathbf{n ( \% )}\end{array}$ \\
\hline Not at all satisfactory & $5(2.5)$ & $8(4.0)$ & $25(12.6)$ & $7(3.5)$ & $21(10.6)$ & $21(10.6)$ \\
\hline Somewhat satisfactory & $27(13.6)$ & $20(10.1)$ & $42(21.1)$ & $31(15.6)$ & $46(23.1)$ & $47(23.6)$ \\
\hline More or less satisfactory & $83(41.7)$ & $72(36.2)$ & $41(20.6)$ & $84(42.2)$ & $58(29.1)$ & $53(26.6)$ \\
\hline Appreciable & $55(27.6)$ & $63(31.7)$ & $47(23.6)$ & $44(22.1)$ & $38(19.1)$ & $41(20.6)$ \\
\hline Excellent & $29(14.6)$ & $36(18.1)$ & $44(22.1)$ & $33(16.6)$ & $20(10.1)$ & $26(13.1)$ \\
\hline
\end{tabular}

Table 3: Comparison of services between private and public hospitals

\begin{tabular}{|l|c|c|c|}
\hline Service & Private Hospital & Public Hospital & $\boldsymbol{p}$-value \\
\hline Doctors service & $3.5 \pm 0.9$ & $3.3 \pm 1.1$ & 0.05 \\
\hline Nurse service & $3.8 \pm 1.0$ & $3.2 \pm 1.0$ & $<0.001$ \\
\hline Service of other staff & $4.0 \pm 1.0$ & $1.2 \pm 1.0$ & $<0.001$ \\
\hline Cleanliness & $3.7 \pm 1.0$ & $3.0 \pm 1.0$ & $<0.001$ \\
\hline Investigation facility & $3.5 \pm 1.0$ & $2.5 \pm 1.1$ & $<0.001$ \\
\hline Medicine supply & $3.7 \pm 1.0$ & $2.4 \pm 1.1$ & $<0.001$ \\
\hline
\end{tabular}


Table 4: Factors influencing further utilization of hospital facilities

\begin{tabular}{|l|c|c|c|}
\hline Variables & $\begin{array}{c}\text { Further utilize hospital } \\
\text { facility }\end{array}$ & $\begin{array}{c}\text { Will not utilize hospital } \\
\text { facility }\end{array}$ & $p$-value \\
\hline Respondents n(\%) & $153(76.9)$ & $46(23.1)$ & 0.00 \\
\hline Doctors services & $3.6 \pm 1.0$ & $2.8 \pm .7$ & 0.00 \\
\hline Nurse services & $3.7 \pm 1.0$ & $2.9 \pm 1.0$ & 0.012 \\
\hline Other staff services & $3.4 \pm 1.4$ & $2.9 \pm 1.2$ & 0.002 \\
\hline Cleanliness & $3.4 \pm 1.1$ & $3.0 \pm 0.9$ & 0.000 \\
\hline Investigation facility & $3.1 \pm 1.2$ & $2.4 \pm 1.0$ & 0.000 \\
\hline Medicine supply & $3.2 \pm 1.2$ & $2.4 \pm 0.9$ & 0.000 \\
\hline Total service score & $20.3 \pm 5.8$ & $15.8 \pm 4.4$ & 0.000 \\
\hline Cost of services in USD & $383.84 \pm 491.85$ & $822.42 \pm 1142.42$ & \\
\hline
\end{tabular}

mentioned that they would avail the facility of same hospital in their further ailment and rest of the patients were disappointed with the hospital services that they would not further visit the same hospital in his future. Outcome of treatment (cured/ deteriorated/ succumbed), mode of treatment (medical/ surgical) did not influence the future plan. Twenty-nine patients $(29.3 \%)$ who had got the services of private hospitals would not further utilize the services, and this dissatisfaction rate is significantly higher $(p=0.02)$ than that of public hospitals $(17 \%)$. Further utilization of the hospital facility is much more $(p=0.002)$ for those who resided in free bed 68 $(85 \%)$ than that of paying bed $52(82.5 \%)$ and cabin 33 $(58.9 \%)$. All the services and cost of services greatly influenced in the planning of further consumption of hospital facility by the patient from public and private hospitals (Table 4).

Regression analysis showed that quality of services $(p=0.000)$ scored by the patients and cost of services $(p=0.001)$ both factors influenced the plan of future consumption of hospital facility with quality having stronger influences. Type of treatment, type of hospital, educational status and socioeconomic condition did not influence the decision of further consumption of the same hospital in multivariate regression analysis.

\section{Discussion}

Satisfaction and quality goes hand in hand, quality and expenditure also like that. Though several studies have also raised concerns of patient satisfaction ratings as a quality of care marker that may be associated with unexpected outcomes. Patient 'satisfaction', is a crucial element of patient-centered care, the implementation of which has become the focus of wide-scale efforts aimed at improving health and health-care delivery. ${ }^{18,19}$ Quality with reasonable cost is expected. In the developing country like Bangladesh we are fighting against poverty and quality below the standards in health sector. This research has got the novelty of comparing the superiority between cost and service quality in making decision of further utilization of the hospital facility. In this study 4 hospitals reasonably representing the private and public sectors of the country.

Service quality assessed by the consumer in this study revealed the better in private hospitals than that of public hospital. This is in accordance with previous several reports from Bangladesh. ${ }^{4}$ In Nepal, for example, the Government made substantial investments in basic health care; yet utilization remained low because of clients' negative perceptions of public health care. ${ }^{20}$ In Vietnam, poor service in the public sector led to increased use of private providers. ${ }^{21}$ Guldner and Rifkin also showed that in Vietnam and Uganda, poor quality of services in the public sector led to greater use of private providers. ${ }^{21}$ Maximum of poor people $(82.7 \%)$ utilized public hospitals in their ailment in our series. Most of the people of Bangladesh are of poor socio-economic status and they have to avail the services from the public sector. So, it is urgently needed to address the loopholes of the public health sector and accountability of the service providers of this sector must be ensured.

In this study, (12.6\%) patients judged the services of staff (i.e. ayas, ward boys and cleaners) as not at all satisfactory which was for doctors $(2.5 \%)$ and for nurses $(4.0 \%)$. This indicates dissatisfaction was more with ancillary staff. There is an improvement of services of doctors and nurses are noted in this study than the previous reports from Bangladesh which were conducted $10-12$ years back. ${ }^{22,23}$ But appropriate steps should be taken to improve the services of ancillary staff.

The Cost of services was much higher in private hospital than that of public hospital where $82.7 \%$ of poor people went for treatment. The cost of health care is key concern for the patients receiving the service. In the public health sector the cost is low but service delivery is inefficient. ${ }^{22,23}$ On the other hand, private health sector provide almost all quality services which may not and to be afforded by many of clients due to high cost. ${ }^{4}$ Sometimes they have to pay bill at the cost of their household assets. Thus the poor are getting even poor which is unfortunate for the total economy of the country. So, it is urgently needed to address the loopholes of the public health sector and accountability of the service providers of this sector must be ensured. In private hospitals main obstacles for accessibility of patients is high price. The prices in different private hospitals are also extremely variable. Unseen, unexplainable, hidden costs make it unbearable.

Further utilization of same hospital in their ailment was assessed from every patient. In private hospital $17 \%$ were disappointed and will not come back to same hospital and in private hospital $29.3 \%$ will not visit same hospital. It is very interesting that quality of private hospitals as evaluated by the patients were much higher in all aspects than that of public hospitals but significant number will not come back to same hospital. Why the patient of public hospital will come back to same hospital even though they were less satisfied? Possibly the poor people who 
were the consumer public hospital was throttled by their poor financial capability to choose any alternate hospitals. On the other hand patient of private hospital has achieved the golden opportunity by their financial capability to choose alternate hospitals.

Decision of further utilization of hospital was influenced by the service provided by doctors, nurses, other staff, cleanliness, investigation facility and medicine supply by univariate analysis. Recent report is also described that satisfied patients are more likely than the unsatisfied ones to continue using the health care services, maintaining their relationships with specific health care providers and complying with the care regimens. ${ }^{24}$ But future utilization was significantly influenced by the expenditure also. Those who will further utilize the hospital expended less (USD 383.84) than those who will not come back (USD 822.42). In logistic regression analysis quality of service and cost of service influenced the decision with superiority of quality of service with no influence of interpersonal variation, type of outcome of treatment and hospitals. It indicates that patients require service even at reasonable costs. $^{22}$ It is also pertinent to note that health care service providers and planners in Bangladesh are often more concerned about the cost of health care rather than its quality. They feel that people in Bangladesh do not want to pay more for higher service quality. This study suggests that cost is a significant contributor but lesser than quality.

This study has some limitations: small number of sample size and quality of service evaluated in the perspective of patient satisfaction only. It was not further justified with hospital management specialist.

\section{Conclusion}

This study concludes that consumers are more satisfied with the services of private hospital than that of public hospital. Most of the patient $(77 \%)$ will further utilize the same hospital in their future ailment. Further utilization of hospital depends on quality of service and cost of service with superiority of quality of service

This study recommends ensuring quality of health service at an affordable cost. The hospital section of Directorate General of Health Service should make all the private hospitals accountable in fixing the price. Low priced private hospitals could be established to serve the poor people. Charity hospitals organized by voluntary organizations could be examples of quality service for lower socioeconomic group.

\section{References}

1. Abel-Smith B, Rawal P. Can the poor afford 'free' health services? A case study of Tanzania. Health Policy Plann 1992; 7(4):329-41.

2. Levin A, Dmytraczenko T. McEuen M, Ssengooba F, Mangani R, Vandyck G. Costs of maternal health care services in three Anglophone African countries. Int $J$ Health Plann M 2003;18:3-22.

3. Nahar S, Costello A. The hidden cost of 'free' maternity care in Dhaka, Bangladesh. Health Policy Plann 1998; 13(4):417-22.
4. Begum F, Karmakar SS, Alam S, Ullah L. Patients Satisfaction: A comparative study between private and public sector at tertiary level hospital. Med Today 2004; 16(1): 8-13.

5. Russell S. Ability to pay for health care, concepts and evidence. Health Policy Plann 1996;11 (3):219-37.

6. Blas E, Limbambala ME. User-payment, decentralization, and health service utilization in Zambia. Health Policy Plann 2001;16 (Suppl 2):19-28.

7. Collins D, Quick J, Musau S, Kraushaar D, Hussein I. The fall and rise of cost sharing in Kenya: the impact of phased implementation. Health Policy Plann 1996;11:52-63.

8. Mwabu G, Mwanzia J, Liambila W. User charges in government health facilities in Kenya: effect on attendance and revenue. Health Policy Plann 1995;10(2):164-70.

9. Yoder RA. Are people willing and able to pay for health services? Soc Sci Med 1989; 29(1):3542 .

10. Killingsworth J, Hossain N, Hedrick-Wong Y, Thomas S, Rahman A, Begum T. Unofficial fees in Bangladesh: price, equity and institutional issues. Health Policy Plann 1999;14:152-63.

11. Stanton B, Clemens J. User fees for health care in developing countries: a case study of Bangladesh. Soc Sci Med 1989; 29(10):11991205.

12. De Geydnt W. Managing the quality of health care in developing countries. Washington, DC: World Bank, 1995.

13. Calnan M, Katsouyiannopoulos V, Ovcharov VK, Prokhorskas R, Ramic H , Willims S. Major determinants of consumer satisfaction with primary care in different health systems. Fam Prac 1994;11(4):468-78.

14. Kwan M. When the client is the king. Plan Parent Chall 1994;2:37-9.

15. Williams T, Schutt-Aine J. Meeting the needs, client satisfaction studies: a simple, inexpensive way to measure quality. Forum 1995;11 (1): 224.

16. Charles C. How was Your Hospital Stay? Patients Report about Their Care in Care in Canadian Hospitals. Canadian Med Assoc J 1994;150 (11):1813-22.

17. Fitzpatrick R. Survey of Patient Satisfaction: IIDesignating a Questionnaire Conducting a Survey. BMJ 1991; 302:1129-32.

18. Fenton JJ, Jerant AF, Bertakis KD, Franks P. The cost of satisfaction: a national study of patient satisfaction, health care utilization, expenditures, and mortality. Arch Intern Med 2012;172(5):405 -11 .

19. Fisher ES, Wennberg DE, Stukel TA, Gottlieb 
DJ, Lucas FL, Pinder EL. The implications of regional variations in Medicare spending. Part 2: health outcomes and satisfaction with care. $A n n$ Intern Med 2003;138(4):288-98.

20. Lafond AK. Improving the quality of investment in health: lessons on sustainability. Health Policy Plann 1995;10:63-76.

21. Guldner M, Rifkin S. Sustainability in the Health Sector, part 1: Vietnam Case Study, London: Save the Children Fund, 1993.
22. Andaleeb SS. Public and private hospitals in Ban-gladesh: service quality and predictors of hospi-tals choice. Health Policy Plann 2000;15:95-102.

23. Rahman MM, Shahidullah M, Shahiduzzaman M, Rashid HA. Quality of health care from patient perspectives. Bangladesh Med Res Counc Bull 2002;28:87-96.

24. Aldebasi YF, Ahmed MI. Patients' Satisfaction with Medical Services in the Qassim Area. $J$ Clin Diagn Res 2011; 5: 813-17. 